\title{
Mitochondrial Diabetes
}

National Cancer Institute

\section{Source}

National Cancer Institute. Mitochondrial Diabetes. NCI Thesaurus. Code C131859.

Diabetes mellitus caused by mutation(s) in mitochondrial DNA . 